\title{
CPI Aggregation: A New Weighting Scheme
}

\author{
A.F.M. Ataur Rahman ${ }^{1}$, Noor Md. Wasi Uddin ${ }^{2}$ \\ ${ }^{1}$ Department of Economics, North South University Dhaka, Bangladesh \\ ${ }^{2}$ Department of Economics, North South University Dhaka, Bangladesh
}

\begin{abstract}
Consumer Price Index (CPI) of a particular region is primarily calculated through aggregation of individual household observations. This aggregation is done following two schemes, plutocratic and democratic. While both of them are useful for certain purposes, none of them actually give proper attention to poor households. In this study, we have shown that weighting scheme with certain mathematical characteristics can actually produce CPI, which can represent poor households better and thus can be more useful for development-oriented policymaking.
\end{abstract}

Keywords: Consumer price index, Plutocratic, Democratic, Aggregation JEL Classification Code: E3

\section{INTRODUCTION}

$\mathrm{T}$ HE consumer price index CPI is a key decision making macroeconomic variable. CPI measurement leads to inflation calculation which is simultaneously used as a policy tool by monetary authorities and development economists as an indicator of the economic hardship that people in general feel. There are two other similar terms available in literature Cost Of Living Index ${ }^{1}$ (COLI) and Cost Of Goods Index $^{2}$ (COGI). They more or less refer to the same concept with some sophistication in one form or other but those differences are not important for this paper. Interested readers can see ILO (2004).

CPIcalculation requires information about two components, consumption basket and price level. Consumption basket is normally inherited from some past study. The inherited basket is computed through a survey that tries to capture the expenditure pattern of a large number of representative households picked through proper sampling procedure. From expenditure pattern, a consumption basket is created which is considered as representative of household preference. This consumption basket is kept fixed for future reference. The other component, price level is computed through sample survey conducted at different geographic locations at a regular interval. Price of the fixed basket is then computed using price survey data. The price of the basket is then expressed as a percentage of the price of the basket at some base period. This quotient is then referred asCPI ${ }^{3}$. This figure tells us how costly the basket has become compared to the base period.

CPI is also calculated following another procedure where the above procedure is run for $n$ nos of households of a random sample to get individual householdCPI. At this level no averaging is done. Therefore, we get ${ }^{n}$ nos. of individual household CPI s. Then individual household CPI s are aggregated to produce national or regional CPI. This aggregation is normally done following two schemes, plutocratic and

\footnotetext{
Term proposed by A. Konus (1924)

2 Term proposed by Schultze et al. (2002).

${ }^{3}$ Sometimes known as Laspeyres index CPI
}

democratic ${ }^{4}$. Plutocratic scheme assigns weight in proportion to the household expenditure. The household that spends more gets more weight in overall indexing. Democratic scheme puts equal weight in every household. CPI following plutocratic scheme can be considered as realistic but it is biased towards wealthy households compared to the second one.

Economic theory is not quite conclusive about the choice of weighting scheme. To put it another way a modeler can exercise her judgment to pick the weighting scheme according to her requirement. That however can introduce biases towards different income group of the society. Since construction of $\mathrm{CPI}$ in this fashion is essentially a formation of a group index, it is very important to keep parity among different individuals representing the group 5 .

Following this vein researchers have found that inflation calculated using plutocratic index is not representative of average consumer. Muellbauer (1976) using UK data found that an average consumer (correspond to the official CPI) is in the 71st percentile in the household expenditure distribution. Similar measure for Deaton (1998) lies at the 75th percentile of the expenditure distribution. A similar exercise done on Spain by Ruiz-Castillo et al. (2002) found the CPI represented consumer in the 61st percentile of the household expenditure distribution.

Distributional aspects of these two weighting schemes are well known and are mentioned in many studies. Fry and Pashardes (1986) concluded in their study that the plutocratic gap (Difference between plutocratic measure of inflation and democratic measure of inflation ) would be positive or negative according to whether prices have behaved respectively in an anti-rich or an anti-poor manner. Using data of Spain Ruiz-Castillo et all (2003) found that the gap is significant and decreases as inflation increases. However Kokoski

\footnotetext{
${ }^{4}$ Following Prais (1958)

${ }^{5}$ For group index literature see Pollak (1980, 1981), Jorgenson and Slesnick (1983), and Diewert (1983).
} 
(2000) using USA data could not find appreciable differences between these two measures of inflation. Studies like these clearly show that there is a scope for further improvement of these measures. Specially none of the measures is biased towards poor. A welfare-oriented modeler would like to have a measure that would response strongly if there is any change in price pattern that affects the poor more than the rich. To the best of our knowledge such measure is absent in literature. In this paper, we are proposing a new weighting scheme that will be pro poor in the sense that it gives more weight to poor households compared to well off households. The remaining paper is organized as follows. The next section has a theoretical construction of the index and the subsequent section tests the sensitivity of the new index. The section after that has a description of a possible weighting scheme. Then conclusive remarks close the discussion.

\section{THE INDEX}

Let's consider an economy consists of a continuum of households each with positive income in[01]scale. This can be done without loss of generality. They spend their income on different goods and services. Based on their expenditure pattern each household will have unique $\mathrm{CPI}^{6}$. ThisCPI is expected to be dependent on household's income only through expenditure pattern. We are aware of the fact that expenditure pattern can be influenced by other economic and social factors but for the time being we are ignoring those factors and expressing household CPI as a function of household incomeCPI I. With income (I) in $\mathrm{x}$ axis and percentage households having a certain income in y axis we can get a graph that can be called as Income Distribution Function IDF compared to probability distribution function PDF in measure theory. It is not hard to comprehend that this will be a downward sloping continuous curve (continuity comes from assumption) with its integral value with respect to I equal to1.0. Its integral over income will produce Cumulative Income Density Function CIDF something comparable to $\mathrm{CDF}$ of measure theory.
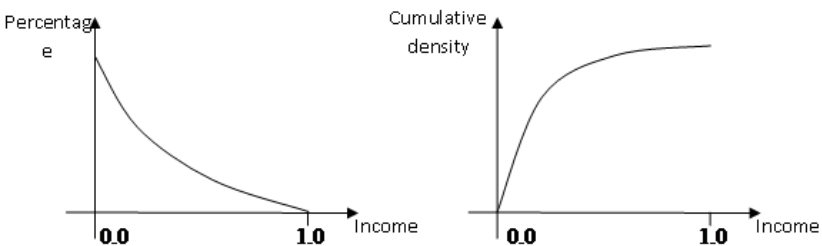

Fig 1(a): Income Distribution Function (IDF)

Fig 1(b): Cumulative Income Density Function

As mentioned earlier, the existing two aggregation schemes are not pro poor. One of them (plutocratic) puts higher weights for rich households and the other one (democratic) puts equal weights on rich and poor households.

In this setup aggregated (democratic) $A C P I$ follows the formula $A C P I_{\text {Dem }}=\int_{0}^{1} C P I(I) d I$. And the aggregated (plutocratic) $C P I$ index will be
$A C P I_{P l u}=\int_{0}^{1} f(I) * C P I(I) d I$. Here $f(I)$ is an increasing function of income. In this study we want to replace $f(I)$ with a new weight scheme $G(I)$. Proposed weight scheme $G(I)$ has two requirements, $G(I) \geq 1.0$ and $G^{\prime}(I)<0$. We can show that if $G(I)$ satisfies these two criteria then we get the expected welfare accommodating $C P I$. Proposed aggregated consumer price index $\left(A C P I_{\text {New }}\right)_{\text {will take a form like }}$ $A C P I_{\text {New }}=\int_{0}^{1} G(I) * C P I(I) d I$

\section{SENSEVITY OF THE INDEX}

Following usual logic of economics, we can assume that $I D F(I)$ is a strictly convex function with first derivative negative. It will be difficult to generalize any pattern for $C P I(I)$ as it can be negative or positive sloped depending upon the microstructure of inflation. For the time being we will assume that $C P I(I)$ is flat, that is inflation is same irrespective of household income. Later we will evaluate increasing and decreasing schemes.First let's see the effect of change in Income distribution Function $(I D F)$ Consider two income distributions $I D F_{1}$ and $I D F_{2}$ Graphically,
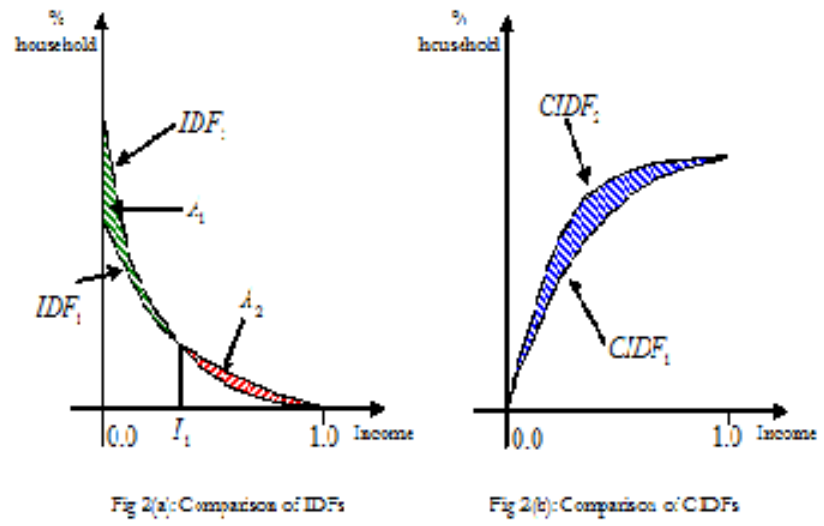

$I D F_{1}$ represents less skewed income distribution than $I D F_{2}$ During this change, the area under $I D F$ curve lost area $A_{2}$ and gained area $A_{1}$ Let's assume that two curves crosses at $I_{1}$ But since the area under the curve is always 1.0 so this gain and loss will be equal. Now we investigate effect of a change in $C P I(I)$ keeping everything else unchanged. Lets assume that the distribution of $C P I_{1}(I)$ is initially flat. Then $C P I(I)$ increases to $C P I_{2}(I)$ To keep things simple we will assume that $C P I_{2}(I)$ is also flat. This change in distribution will make corresponding change in ACPI ACPI measured following democratic weight scheme, let's call that change as $\triangle A C P I_{d e m}$

\footnotetext{
${ }^{6}$ We can calculate that following Laspeyres argument
} 


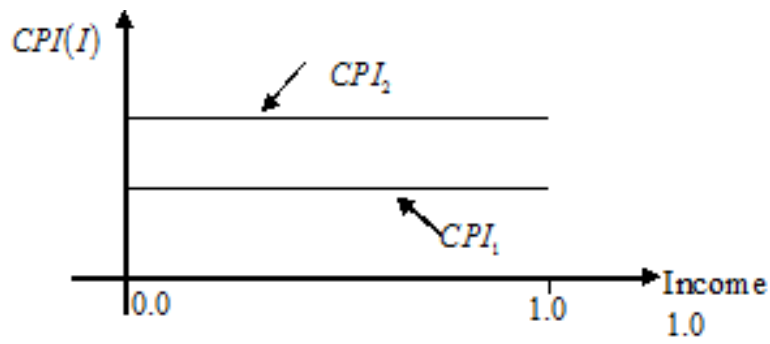

Fig 3: Different schemes of CPI 1.0

$\triangle A C P I_{D e m}$ can be expressed as

$\triangle A C P I_{D e m}=\int_{0}^{1}\left[C P I_{2}(I)-C P I_{1}(I)\right] d I$

$\Rightarrow \triangle A C P I_{D e m}=\left[C P I_{2}(I)-C P I_{1}(I)\right] \int_{0}^{1} d I$

$\Rightarrow \triangle A C P I_{D e m}=\left[C P I_{2}(I)-C P I_{1}(I)\right]$

For new weight scheme $\triangle A C P I_{N e w}$ will be

$\Delta C P I_{\text {New }}=\int_{0}^{1} G(I) *\left[C P I_{2}(I)-C P I_{1}(I)\right] d I$

$\Rightarrow \Delta C P I_{\text {New }}=\left[C P I_{2}(I)-C P I_{1}(I)\right] \int_{0}^{1} G(I) d I$

Now since $G(I) \geq 1$ so is $\int_{0}^{1} G(I) d I$. Which means that $\triangle A C P I_{\text {New }}$ will show a larger impact of change in $C P I(I)$ than $\triangle A C P I_{D e m}$ even when the change in $C P I(I)$ is uniform. Now we will evaluate the case where $C P I(I)$ takes a non-zero slope from an initial zero sloped shape. To make things simple we will assume that $C P I(I)$ conserves its linearity after the change. However, the change will be such that the mean $C P I(I)$ across income will be same so assuming $\mathrm{CPI}_{2}(I)=\alpha I+\beta$ we have

$C P I_{1}(I)=\int_{0}^{1}(\alpha I+\beta) d I \Rightarrow \frac{\alpha}{2}+\beta$. Which means

$\int_{0}^{1}\left(C P I_{2}(I)-C P I_{1}(I)\right) d I=\int_{0}^{1}\left(\alpha I-\frac{\alpha}{2}\right) d I$

Depending upon the value of $\alpha$ the $C P I(I)$ will have either increasing or decreasing trend. If $C P I(I)$ has a decreasing trend, then higher income household will face higher
CPI $(I)$ than lower income household. The opposite will be true if the trend is positive.

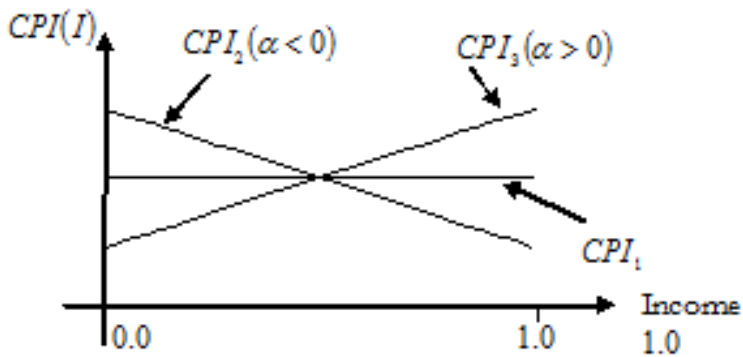

Fig 4: Different schemes of $C P I$

1.0

$\triangle A C P I_{D e m}$ can be expressed as

$\triangle A C P I_{D e m}=\int_{0}^{1}\left(C P I_{2}(I)-C P I_{1}(I)\right) d I$

$\Rightarrow \triangle A C P I_{D e m}=\int_{0}^{1}\left(\alpha I-\frac{\alpha}{2}\right) d I$

$\Rightarrow \triangle A C P I_{D e m}=\frac{\alpha}{2}\left(I^{2}-I\right)_{0}^{1}$

$\Rightarrow \triangle A C P I_{D e m}=0$

For new weight scheme $\triangle A C P I_{\text {New }}$ will be

$\triangle A C P I_{\text {New }}=\int_{0}^{1} G(I) *\left\{C P I_{2}(I)-C P I_{1}(I)\right\} d I$

$\Rightarrow \triangle A C P I_{\text {New }}=\int_{0}^{1}\left\{G(I) *\left(\alpha I-\frac{\alpha}{2}\right)\right\} d I$

$\Rightarrow \triangle A C P I_{\text {New }}=\left.\frac{\alpha}{2}\left[G(I) *\left(I^{2}-I\right)-\int\left\{\frac{\partial}{\partial I} G(I)\right\}\left(I^{2}-I\right) d I\right]\right|_{0} ^{1}$

$\Rightarrow \Delta A C P I_{\text {New }}=\left.\frac{\alpha}{2}\left[-\int\left\{\frac{\partial}{\partial I} G(I)\right\}\left(I^{2}-I\right) d I\right]\right|_{0} ^{1}$

Now assuming $G^{\prime}(I)<0$ and $\left(I^{2}-I\right)<0$ for the range of $I$ in consideration, we can have following conclusions:

\begin{tabular}{|l|l|l|}
\hline Cases & Physical interpretation & \\
\hline$\alpha>0$ & $\begin{array}{l}\text { Higher income group } \\
\text { faces higher CPI } \\
\text { Lower income group } \\
\text { faces lower CPI }\end{array}$ & \\
\hline
\end{tabular}




\begin{tabular}{|l|ll|l|}
$\alpha<0$ & $\begin{array}{l}\text { Higher income group } \\
\text { faces lower CPI } \\
\text { Lower income group } \\
\text { faces higher CPI }\end{array}$ & $\triangle A C P I_{\text {New }}>0$ \\
\hline
\end{tabular}

This means that the new aggregation scheme better reflects the condition of low income group compared to high income group as expected.

\section{The Weight SCheme $G(I)$}

Weight scheme $G(I)$ is important for our purpose. We have mentioned two properties of it, $G(I) \geq 1.0$ and $G^{\prime}(I)<0$. A function with such properties is not difficult to find. On esuch example could be $G(I)=\frac{1}{(I+a)}$, where $a$ is a positive real number. However, what is difficult is to put proper explanation for picking a particular function for this purpose. One candidate of $G(I)$ can be marginal utility function. This has a nice intuitive explanation as well. If we use marginal utility function as $G(I)$ then what we basically do is to weight $C P I$ of each income group by how much they value their marginal income. If we use this as weight scheme then we implicitly argue that we are evaluating households according to the worthiness of their income. This will also satisfy the technical requirement as marginal utility is expected to be positive.

\section{CONCLUSION}

For understandable reason, we have not compared Plutocratic aggregation scheme with our new scheme. Comparing with democratic scheme, we have found that the new scheme is better in the sense that it reflects the condition of poor household more in case of increasing inflation. This scheme may not be realistic in the sense that it gives low weight to the households that spend more and thus become the dominant portion of the expenditure figure but it is "realistic" in the sense that it is giving more importance to the poor households which are affected more in case of an increase in inflation. It reflects the increase in hardship better than other available aggregation methods.

\section{Bibliography}

[1] Fry, Vanessa, and Panos Pashardes, 1986, "The RPI and the Cost of Living," Report Series No. 22 (London: Institute for Fiscal Studies).

[2] Jorgenson, Dale W., and Daniel T. Slesnick, "Individual and Social Cost-of-Living Indexes." In W. E. Diewert and C. Montmarquette, eds. Price Level Measurement. Statistics Canada, 1983, 241-323.

[3] Konus, A. (1924) "The Problem of the True Index of the Cost of Living," translated in Econometrica (1939), vol. 7, pp. 10-29

[4] Kokoski, M. Alternative CPI aggregations: two approaches, Monthly Labor Review, November 2000, pp 31-39

[5] Schultze, C. et al. (2002). At What Price? Conceptualizing and Measuring Cost-of- Living and Price Indexes. Washington: National Academy Press

[6] Prais, Sigbert J., 1958, “Whose Cost of Living?" Review of Economic Studies, Vol. 26, pp. 126-34

[7] Pollak, R.A. (1980). "Group Cost-of-Living Indexes". American Economic Review 70, 273-78.
[8] International Labor Office (2004) Consumer Price Index Manual: Theory and Practice, International Labor Office: Geneva (Available at http://www.ilo.org/public/english/bureau/stat/guides/cpi/)

[9] Pollak, R.A. (1981). "The Social Cost-of-Living Index" Journal of Public Economics 15, 311-36

[10] Pollak, Robert, 1998, "The Consumer Price Index: A Research Agenda and Three Proposals," Journal of Economic Perspectives, Vol. 12, No. 1, pp. 69-78.

[11] Muellbauer, John, 1976, "The Political Economy of Price Indices," Birkbeck Discussion Paper No. 22 (London: Birkbeck College).

[12] Diewert, W. E., "The Theory of the Cost-of- Living Index and the Measurement of Welfare Change." In W. E. Diewert and C. Montmarquette, eds. Price Level Measurement. Statistics Canada, 1983, 163-233.

[13] Deaton, Angus, 1998, "Getting Prices Right: What Should Be Done?" Journal of Economic Perspectives, Vol. 12, No. 1, pp. 37-46.

[14] Ruiz-Castillo, Javier, Eduardo Ley, and Mario Izquierdo, 2002, “Distributional Aspects of the Quality Change Bias in the CPI: Evidence from Spain," Economics Letters, Vol. 76 (June), pp. 137-44.

[15] Ruiz-Castillo, Javier, Eduardo Ley, and Mario Izquierdo, "The Plutocratic Gap in the CPI: Evidence from Spain", IMF Staff Papers, 2003,Vol.50, No. 1

[16] J.S. Bridle, "Probabilistic Interpretation of Feedforward Classification Network Outputs, with Relationships to Statistical Pattern Recognition," Neurocomputing - Algorithms, Architectures and Applications, F. FogelmanSoulie and J. Herault, eds., NATO ASI Series F68, Berlin: Springer-Verlag, pp. 227-236, 1989. (Book style with paper title and editor)

[17] W.-K. Chen, Linear Networks and Systems. Belmont, Calif.: Wadsworth, pp. 123-135, 1993. (Book style)

[18] H. Poor, "A Hypertext History of Multiuser Dimensions," MUD History, http://www.ccs.neu.edu/home/pb/mudhistory.html. 1986. (URL link *include year)

[19] K. Elissa, "An Overview of Decision Theory," unpublished. (Unplublished manuscript)

[20] R. Nicole, "The Last Word on Decision Theory," J. Computer Vision, submitted for publication. (Pending publication)

[21] C. J. Kaufman, Rocky Mountain Research Laboratories, Boulder, Colo., personal communication, 1992. (Personal communication)

[22] D.S. Coming and O.G. Staadt, "Velocity-Aligned Discrete Oriented Polytopes for Dynamic Collision Detection," IEEE Trans. Visualization and Computer Graphics, vol.14, no. 1, pp. 1-12, Jan/Feb 2008, doi:10.1109/TVCG.2007.70405. (IEEE Transactions )

[23] S.P. Bingulac, "On the Compatibility of Adaptive Controllers," Proc. Fourth Ann. Allerton Conf. Circuits and Systems Theory, pp. 8-16, 1994. (Conference proceedings)

[24] H. Goto, Y. Hasegawa, and M. Tanaka, "Efficient Scheduling Focusing on the Duality of MPL Representation," Proc. IEEE Symp. Computational Intelligence in Scheduling (SCIS '07), pp. 57-64, Apr. 2007, doi:10.1109/SCIS.2007.367670. (Conference proceedings)

[25] J. Williams, "Narrow-Band Analyzer," PhD dissertation, Dept. of Electrical Eng., Harvard Univ., Cambridge, Mass., 1993. (Thesis or dissertation)

[26] E.E. Reber, R.L. Michell, and C.J. Carter, “Oxygen Absorption in the Earth's Atmosphere," Technical Report TR-0200 (42046)-3, Aerospace Corp., Los Angeles, Calif., Nov. 1988. (Technical report with report number)

[27] L. Hubert and P. Arabie, "Comparing Partitions," J. Classification, vol. 2, no. 4, pp. 193-218, Apr. 1985. (Journal or magazine citation)

[28] R.J. Vidmar, "On the Use of Atmospheric Plasmas as Electromagnetic Reflectors," IEEE Trans. Plasma Science, vol. 21, no. 3, pp. 876-880, available at http://www.halcyon.com/pub/journals/21ps03vidmar, Aug. 1992. (URL for Transaction, journal, or magzine)

[29] J.M.P. Martinez, R.B. Llavori, M.J.A. Cabo, and T.B. Pedersen, "Integrating Data Warehouses with Web Data: A Survey," IEEE Trans. Knowledge and Data Eng., preprint, 21 Dec. 2007, doi:10.1109/TKDE.2007.190746.(PrePrint) 